\title{
Evaluation of the budding and depth of invasion (BD) model in oral tongue cancer biopsies
}

\author{
Almangush, Alhadi
}

2018-02

Almangush, A , Leivo , I , Siponen, M , Sundquist , E, Mroueh , R , Mäkitie , A A , Soini , Y , Haglund , C , Nieminen , P \& Salo , T 2018 , ' Evaluation of the budding and depth of invasion (BD) model in oral tongue cancer biopsies ' , Virchows Archiv , vol. 472 , no. 2 , pp. 231-236 . https://doi.org/10.1007/s00428-017-2212-1

http://hdl.handle.net/10138/301257

https://doi.org/10.1007/s00428-017-2212-1

publishedVersion

Downloaded from Helda, University of Helsinki institutional repository.

This is an electronic reprint of the original article.

This reprint may differ from the original in pagination and typographic detail.

Please cite the original version. 


\title{
Evaluation of the budding and depth of invasion (BD) model in oral tongue cancer biopsies
}

\author{
Alhadi Almangush ${ }^{1,2,3} \cdot$ Ilmo Leivo $^{4}$ - Maria Siponen ${ }^{5,6,7}$ - Elias Sundquist ${ }^{5,8}$. \\ Rayan Mroueh $^{9}$ - Antti A. Mäkitie ${ }^{9}$ - Ylermi Soini ${ }^{10}$ • Caj Haglund ${ }^{11,12}$. \\ Pentti Nieminen $^{13}$ - Tuula Salo ${ }^{2,5,8,14}$
}

Received: 11 May 2017 / Revised: 19 July 2017 / Accepted: 24 July 2017 /Published online: 2 August 2017

(C) Springer-Verlag GmbH Deutschland 2017

\begin{abstract}
It is of great clinical importance to identify simple prognostic markers from preoperative biopsies that could guide treatment planning. Here, we compared tumor budding (B), depth of invasion (D), and the combined scores (i.e., budding and depth of invasion (BD) histopathologic model) in preoperative biopsies and the corresponding postoperative specimens of oral tongue squamous cell carcinoma (OTSCC). Tumor budding and depth of invasion were evaluated in the pre- and postoperative samples from 100 patients treated for OTSCC. Sensitivity and specificity statistics were used. Our results showed statistically significant $(P<0.001)$ relationship between pre- and postoperative BD scores. There was an agreement between the pre- and postoperative BD model scores in 83 cases $(83 \%$ ) with $57.1 \%$ sensitivity (95\% CI 39.4 to $73.7 \%$ ) and $96.9 \%$ specificity (95\% CI 89.3 to $99.6 \%$ ). Our findings suggest that the $\mathrm{BD}$ model, analyzed from representative biopsies, could be used for the treatment planning of OTSCC.
\end{abstract}

Alhadi Almangush

alhadi.almangush@helsinki.fi

1 Department of Pathology, University of Helsinki, Helsinki, Finland

2 Department of Oral and Maxillofacial Diseases, University of Helsinki, Helsinki, Finland

3 Institute of Dentistry, University of Misurata, Misurata, Libya

4 Department of Pathology, University of Turku, Turku, Finland

5 Cancer and Translational Medicine Research Unit, University of Oulu, Oulu, Finland

6 Department of Oral and Maxillofacial Diseases, Kuopio University Hospital, Kuopio, Finland

7 Institute of Dentistry, University of Eastern Finland, Kuopio, Finland

8 Medical Research Center, Oulu University Hospital, Oulu, Finland
Keywords Oral tongue cancer · Tumor budding · Tumor depth $\cdot$ BD model $\cdot$ Prognosis

\section{Introduction}

Oral or mobile tongue squamous cell carcinoma (OTSCC) has shown increased incidence in several countries [1]. Aggressive behavior and poor prognosis are reported even at early stages of the tumor [2, 3]. A preoperative biopsy is routinely obtained for histopathologic diagnosis of suspicious tongue lesions. Although several prognostic markers for OTSCC have been published, there is still a lack of validated markers that could easily be evaluated in preoperative OTSCC histological sections. Therefore, identification of prognostic marker(s) in biopsy specimens would be a valuable tool for

9 Department of Otorhinolaryngology - Head and Neck Surgery, Helsinki University Hospital and University of Helsinki, Helsinki, Finland

10 Department of Pathology and Forensic Medicine, University of Eastern Finland, Kuopio, and Cancer Center of Eastern Finland, Kuopio, Finland

11 Department of Surgery, University of Helsinki and Helsinki University Hospital, Helsinki, Finland

12 Research Programs Unit, Translational Cancer Biology, University of Helsinki, Helsinki, Finland

13 Medical Informatics and Statistics Research Group, University of Oulu, Oulu, Finland

14 HUSLAB, Department of Pathology, Helsinki University Central Hospital, University of Helsinki, Helsinki, Finland 
treatment planning (local resection with or without the neck dissection).

We have previously introduced the budding and depth (BD) histopathologic model as a prognostic tool in OTSCC [4]. The prognostic value of this model has been validated in cohorts of oral squamous cell carcinomas (OSCC) [5, 6]. In these studies, the BD model was shown to have superior prognostic power when compared to the other previously introduced histopathologic grading systems, such as WHO grading [7], malignancy grading of the deep invasive margins [8], and histological risk score [9]. Additionally, tumor budding is associated with the progression and prognosis of several epithelial cancers, such as head and neck [10], esophageal [11], colorectal [12], pancreatic [13], lung [14], and breast [15]. Specifically in OTSCC, budding correlates with occult cervical lymph node metastasis and poor prognosis [16, 17]. Similarly, the depth of invasion is a prognostic marker for OTSCC [17]. Recently, pre- and postoperative samples were compared in a study of 91 OSCC cases, and it was shown that both budding and tumor depth correlated significantly with relapse-free survival [18]. To our knowledge, however, there is no sizeable cohort where the BD model has been tested in OTSCC biopsies and compared to the corresponding postoperative OTSCC samples. The aim of this study was to analyze the sensitivity and specificity of preoperative BD scores of hematoxylin and eosin-stained OTSCC biopsies compared to the postoperative BD scores of the corresponding cases.

\section{Material and methods}

Hematoxylin and eosin (HE)-stained slides from pre- and postoperative samples of 145 patients diagnosed with OTSCC at the University Hospitals of Helsinki, Kuopio, and Oulu between the years 1981 and 2016 were retrieved for this study. The use of pre- and postoperative samples and the data inquiry was approved by the ethics committees of Helsinki, Kuopio, and Oulu University Hospitals. All patients were diagnosed by incisional biopsy and treated by surgical excision of the tumor. Patients without either pre- or postoperative counterparts available were excluded. Cases received preoperative therapy were also excluded. A total of 100 cases were eligible for the comparative analyses.

Tumor budding (B) was defined as the presence of single cancer cell or cluster of less than five cancer cells. The invasive front (IF) was evaluated under low magnification $(\times 4)$, and then, the field with the highest density of tumor budding was counted under high magnification $(\times 20)$. The depth of tumor invasion (D) was measured from the surface of the tumor to the deepest point of invasion. The scoring was performed by an independent researcher (AA) and reviewed by an experienced head and neck pathologist (IL). BD scores were assigned as previously described [4] (Fig. 1). In brief, score 0 refers to $<5$ buds at the IF and $<4 \mathrm{~mm}$ in depth. Score 1 refers to either presence of $\geq 5$ buds at the IF or a deep tumor of $\geq 4 \mathrm{~mm}$ in depth. Score 2 refers to the presence of $\geq 5$ buds at the IF and a deep tumor of $\geq 4 \mathrm{~mm}$ in depth.

Statistical analysis All analyses were performed with IBM SPSS version 20. The statistical significance of the relationship between pre- and postoperative measures was evaluated using chi-square test. For sensitivity and specificity statistics with their $95 \%$ confidence intervals (95\% CI), BD scores of low and intermediate were combined together (low and intermediate vs. high) to evaluate the predictive power of preoperative score for the postoperative score of the corresponding sample.

\section{Results}

\section{Patient characteristics}

One case received preoperative therapy and was therefore excluded from our analysis. A total of 100 patients were enrolled in the statistical analyses of the study. There were 51 males (51.0\%). Stage distribution was as follows: 41 cases $(41.0 \%)$ were assigned as stage I, $40(40.0 \%)$ as stage II, $9(9.0 \%)$ as stage III, and $10(10.0 \%)$ as stage IV. The mean age at diagnosis was 60.8 years (range 27 to 91 years). All tumors were located on the oral tongue (OTSCC).

\section{Histopathologic correlation between biopsy specimens and surgical resection specimens}

\section{Tumor budding}

The number of tumor budding in biopsies ranged from 0 to 13 buds (median 1, mean 3.5), and that for the corresponding postoperative samples ranged from 0 to 17 buds (median 3, mean 3.9). Of the cases, 82 (82\%) had the same B category (low $<5$ buds or high $\geq 5$ buds) in the pre- and postoperative samples. The association between pre- and postoperative B was statistically significant $(P$ value of chi-square test $<0.001)$. The preoperative scores showed a good sensitivity of $59.1 \%$ (95\% CI 43.3 to $73.7 \%$ ) and a high specificity of $100 \%$ (95\% CI 93.6 to $100 \%$ ) in predicting the postoperative score of the same case (Table 1).

\section{Depth of invasion}

In biopsy specimens, depth values ranged from 0.5 to $10 \mathrm{~mm}$ (mean $4.1 \mathrm{~mm}$, median $4 \mathrm{~mm}$ ), and those for the corresponding postoperative samples ranged from 0.5 to $23 \mathrm{~mm}$ (mean $6.3 \mathrm{~mm}$, median $6 \mathrm{~mm}$ ). Of the cases, 77 

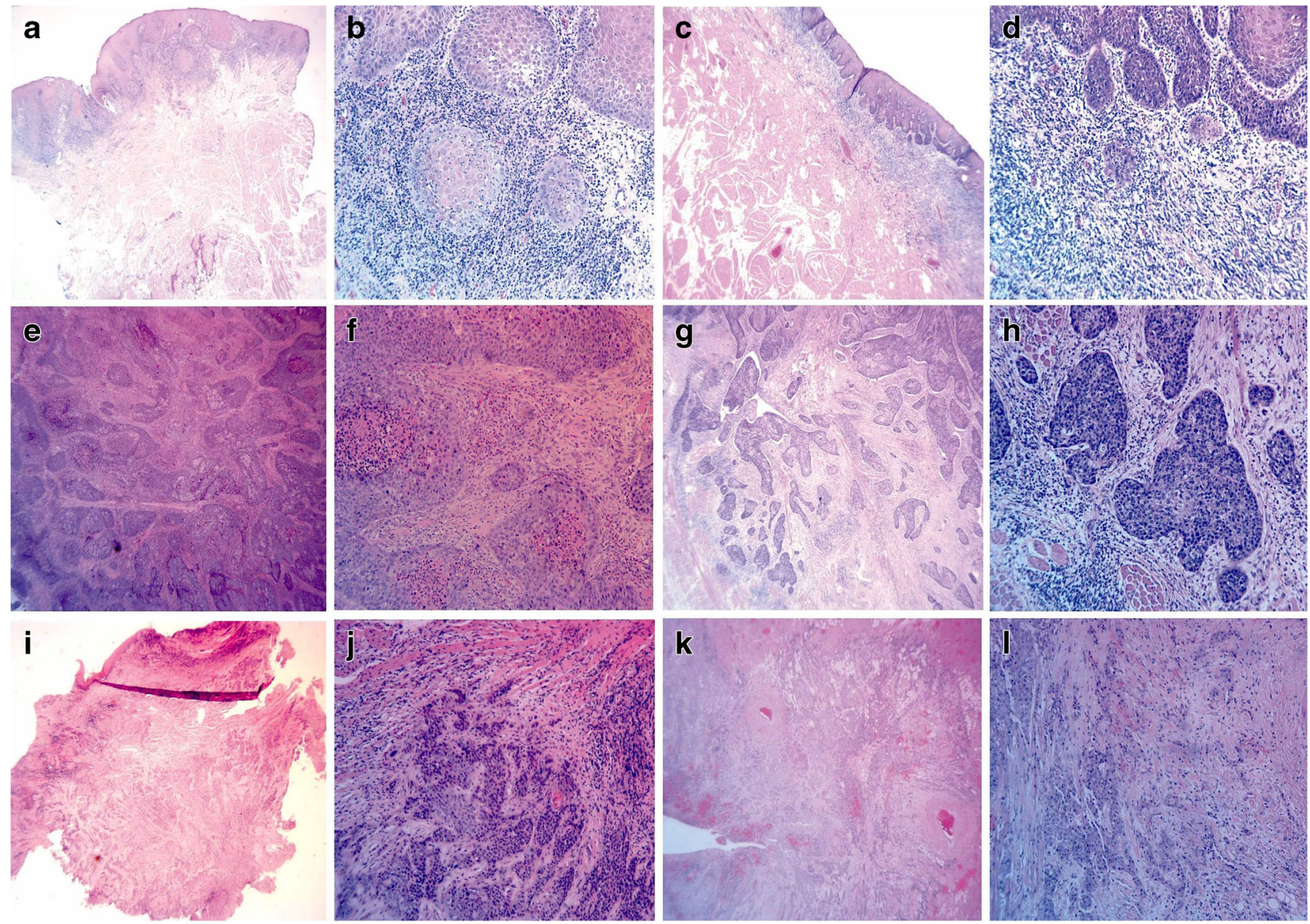

Fig. 1 Score 0 (a-d): Small magnification of preoperative biopsy (a) of superficial tumor without tumor budding in the higher magnification (b) of the IF. Small magnification for the corresponding resection specimen (c), and higher magnification of the IF (d). Score 1 (e-h): Small magnification of preoperative biopsy of very deep tumor (e), without tumor budding at the invasive front (f). Small magnification of the corresponding resection specimen ( $\mathbf{g}$ ) and higher magnification of the

IF (h) which shows no tumor budding. Score 2 (i-l): Small magnification of preoperative biopsy of very deep tumor (i), with the presence of tumor budding at the IF in the higher magnification (j). Small magnification of the corresponding resection specimen $(\mathbf{k})$ and higher magnification of the IF (l) which shows tumor budding. IF invasive front. Small magnification, $\times 20$. Higher magnification, $\times 100$

(77.0\%) had the same D category (superficial $<4 \mathrm{~mm}$ or deep $\geq 4 \mathrm{~mm}$ ) in the pre- and postoperative samples. The relationship between the pre- and postoperative $\mathrm{D}$ value was statistically significant $(P$ value of chi-square test

$<0.001)$. The preoperative measurement showed a high predictive power of postoperative measurement with $77.1 \%$ sensitivity (65.6 to $86.3 \%$ ) and $76.7 \%$ specificity (57.2 to $90.1 \%$ ) (Table 1 ).

Table 1 Distribution of cases according to preoperative and postoperative scores

\begin{tabular}{llll}
\hline & Postoperative budding & & Total $n(\%)$ \\
Preoperative budding & Low $n(\%)$ & High $n(\%)$ & \\
• Low & $56(75.7)$ & $18(24.3)$ & $74(100)$ \\
$\bullet$ High & 0 & $26(100)$ & $26(100)$ \\
& Postoperative depth & & \\
Preoperative depth & Superficial $n(\%)$ & Deep $n(\%)$ & $39(100)$ \\
- Superficial & $23(59.0)$ & $16(41.0)$ & $61(100)$ \\
- Deep & $7(11.5)$ & $54(88.5)$ & \\
& Postoperative BD score & & \\
Preoperative BD score & Low or intermediate $n(\%)$ & High $n(\%)$ & $78(100)$ \\
• Low or intermediate & $63(80.8)$ & $15(19.2)$ & $22(100)$ \\
• High & $2(9.1)$ & $20(90.9)$ & \\
\hline
\end{tabular}




\section{BD model}

For the preoperative samples, 35 cases $(34.7 \%)$ had BD score 0,43 cases $(42.6 \%)$ had score 1 , and 23 cases $(22.8 \%)$ had score 2 . In the postoperative samples, 21 cases $(20.8 \%)$ had score 0,44 cases $(43.6 \%)$ had score 1 , and 36 cases (35.6\%) had score 2 . There was a significant association between scores of BD model and cTNM stage (two-sided $P=0.001$ ). The BD histological model showed a highly significant relationship between pre- and postoperative measurements ( $P$ value of chi-square test $<0.001)$. There was an agreement between the pre- and postoperative scores of the BD model in 83 cases $(83.0 \%$ ) with $57.1 \%$ sensitivity (95\% CI 39.4 to $73.7 \%$ ) and $96.9 \%$ specificity (95\% CI 89.3 to $99.6 \%$ ) (Table 1).

\section{Discussion}

During the histopathologic evaluation of OTSCC, pathologists attempt to identify histopathological prognostic markers. Identification of such markers, especially in early-stage tumors, could guide clinical treatment decisions. Recently, our group suggested the $\mathrm{BD}$ model as a prognostic tool in a large multicenter cohort of OTSCC [4]. This model is now also validated in other cohorts of OSCC $[5,6]$. In the multivariate analysis of these previous studies, BD model showed superior prognostic power compared to the other parameters. In this study, we demonstrated a significant relationship between the BD scores in the pre- and postoperative OTSCC samples. This finding is particularly useful for making treatment decisions at an early stage, but occasionally highly aggressively behaving cases. The use of BD model in daily practice might provide a reliable additional prognostic tool that could overcome the shortcoming of currently used preoperative tumor size staging (T) and histopathological biopsy grading. Both of these commonly used preoperative analyses, tumor clinical size measurement and cancer cell differentiation grading, have been criticized for their low prognostic power of the cancer $[2,19]$.

Cancer cell can invade individually or in a collection of cell clusters [20]. Different patterns for head and neck cancers invasion have been suggested, including worst pattern of invasion (WPOI) and tumor budding. WPOI was introduced as a part of histologic risk model [21], and it was shown as a useful prognostic marker in early OTSCC [2]. However, tumor satellites, which represent type 5 WPOI and are defined as tumor island/s located $1 \mathrm{~mm}$ or more away from the main tumor or next closest satellite, require the evaluation of all tumor sections [21], and thus, this score remains inapplicable for biopsy specimen analyses. On the other hand, tumor budding is a recently introduced histopathologic pattern which has been reported as a promising prognosticator in several carcinomas $[10-13,15]$ and has been successfully evaluated in preoperative biopsy $[18,22]$. A five-bud cutoff point has widely been used in OSCC [17, 23-25] and other cancers [26, 27 to stratify the tumors into low-risk ( $<5$ buds) or high-risk groups ( $\geq 5$ buds).

Depth of invasion has been reported as a significant prognosticator in OTSCC $[17,28,29]$. The cutoff point of 4-mm depth is widely accepted and has been validated in recent OTSCC studies [2, 30, 31]. Of note, a meta-analysis has also concluded that $4 \mathrm{~mm}$ would be an optimal cutoff point [32]. In this study, we found a good correlation between the depth in the preoperative and postoperative samples when we stratified the cases into two categories (superficial $<4 \mathrm{~mm}$ vs. deep $\geq 4 \mathrm{~mm}$ ). However, when the exact measurements (i.e., quantitative) of pre- and postoperative depth were compared, the correlations were low. This was expected as in the postoperative samples, the measurement could be taken at several sites of the cancer sections, while in the preoperative biopsies, the measurement is possible only from a limited tumor area. More importantly, in the present series, both measurements were in the same category (superficial $<4 \mathrm{~mm}$ or deep $\geq 4 \mathrm{~mm}$ ) in $77 \%$ of the cases. For the remaining cases, low-quality biopsies (e.g., superficial samples missing the deepest part of the tumor) did not allow accurate measurement of the invasion depth. The validity of preoperative tumor depth evaluation by ultrasonography or magnetic resonance imaging (or both) has been confirmed in many studies [33-36]. This should be considered as a surrogate method in case the entire tumor thickness is unclear in the preoperative biopsy. Additionally, the depth of invasion evaluation from fresh-frozen intraoperative sections has shown a strong association with the postoperative measurement [37]. Such procedures could also reduce the inaccuracy in the preoperative biopsy measurement.

Similar to our multicenter Finnish study of 100 OTSCC patients, a Japanese group has recently published a study of 91 OSCC cases from tongue and floor of mouth [18]. They concluded that the budding scores in particular showed a significant correlation between biopsies and corresponding resected specimens. Such a correlation was also observed with the depth measurements, but with less accuracy. These two separate cohorts both highlight the usefulness of preoperative evaluation of the budding and in cases of representative, sufficiently deep biopsies, also, the depth of invasion. Of note, the results of our current study are based on SCC cases from the mobile tongue only, a subsite of oral cavity, in which SCCs are mostly human papilloma virus (HPV) negative [38, 39]. In contrast, HPV-positive head and neck SCCs most commonly occur in the oropharynx (including base of the tongue) and are reported to have a favorable prognosis [40].

All our cases that had different scores (about 17\%) in the BD model in the preoperative compared to postoperative samples had non-representative biopsies. These biopsies were often badly fragmented and too superficial, or had some technical artifacts, such as tangential cutting. Therefore, we strongly recommend that clinicians carefully take a large (at least $4 \mathrm{~mm}$ 
wide and $4 \mathrm{~mm}$ deep) biopsy (or several biopsies from different parts of the tumor) that includes the deepest part of the tumor. A high-quality biopsy would allow the pathologist to evaluate the BD model accurately. However, if the quality of the biopsy is low (too shallow, fragmented, or not in the deepest area), the BD model evaluation would be inadequate.

Several previous findings have shown that the BD model is a simple and predictive histopathological grading system for OSCC patients [4-6, 18]. Here, we demonstrated that in satisfactory biopsies, the BD model can be evaluated from HEstained slides, and the BD scores significantly corresponded to the scores of postoperative tumor resection samples.

Compliance with ethical standards Institutional review board approval was obtained from the ethics committees of Helsinki, Kuopio, and Oulu University Hospitals.

Funding This study was supported by the Finnish Dental Society (Alhadi Almangush), the Maritza and Reino Salonen Foundation (Ilmo Leivo), and the Finnish Cancer Society (Tuula Salo).

Conflict of interest The authors declare that they have no conflict of interest.

\section{References}

1. Ng JH, Iyer NG, Tan MH, Edgren G (2016) Changing epidemiology of oral squamous cell carcinoma of the tongue: a global study. Head Neck. doi:10.1002/hed.24589

2. Almangush A, Bello IO, Coletta RD, Makitie AA, Makinen LK, Kauppila JH, Pukkila M, Hagstrom J, Laranne J, Soini Y, Kosma VM, Koivunen P, Kelner N, Kowalski LP, Grenman R, Leivo I, Laara E, Salo T (2015) For early-stage oral tongue cancer, depth of invasion and worst pattern of invasion are the strongest pathological predictors for locoregional recurrence and mortality. Virchows Arch 467:39-46. doi:10.1007/s00428-015-1758-Z

3. Ganly I, Patel S, Shah J (2012) Early stage squamous cell cancer of the oral tongue - clinicopathologic features affecting outcome. Cancer 118:101-111. doi:10.1002/cncr.26229

4. Almangush A, Coletta RD, Bello IO, Bitu C, Keski-Santti H, Makinen LK, Kauppila JH, Pukkila M, Hagstrom J, Laranne J, Tommola S, Soini Y, Kosma VM, Koivunen P, Kowalski LP, Nieminen P, Grenman R, Leivo I, Salo T (2015) A simple novel prognostic model for early stage oral tongue cancer. Int $\mathrm{J}$ Oral Maxillofac Surg 44:143-150. doi:10.1016/j.ijom.2014.10.004

5. Sawazaki-Calone I, Rangel A, Bueno AG, Morais CF, Nagai HM, Kunz RP, Souza RL, Rutkauskis L, Salo T, Almangush A, Coletta RD (2015) The prognostic value of histopathological grading systems in oral squamous cell carcinomas. Oral Dis 21:755-761. doi: 10.1111/odi.12343

6. Strieder L, Coutinho-Camillo CM, Costa V, da Cruz Perez DE, Kowalski LP, Kaminagakura E (2017) Comparative analysis of three histologic grading methods for squamous cell carcinoma of the lip. Oral Dis 23:120-125. doi:10.1111/odi.12586

7. Barnes LEJ, Reichart P, Sidransky D (2005) World Health Organization classification of tumors. Pathology and genetics of head and neck tumours. IARC Press, Lyon

8. Bryne M, Koppang HS, Lilleng R, Kjaerheim A (1992) Malignancy grading of the deep invasive margins of oral squamous cell carcinomas has high prognostic value. J Pathol 166:375-381. doi:10.1002/path.1711660409

9. Brandwein-Gensler M, Teixeira MS, Lewis CM, Lee B, Rolnitzky L, Hille JJ, Genden E, Urken ML, Wang BY (2005) Oral squamous cell carcinoma: histologic risk assessment, but not margin status, is strongly predictive of local disease-free and overall survival. Am J Surg Pathol 29:167-178

10. Almangush A, Salo T, Hagstrom J, Leivo I (2014) Tumour budding in head and neck squamous cell carcinoma - a systematic review. Histopathology 65:587-594. doi:10.1111/his.12471

11. Almangush A, Karhunen M, Hautaniemi S, Salo T, Leivo I (2016) Prognostic value of tumour budding in oesophageal cancer: a metaanalysis. Histopathology 68:173-182. doi:10.1111/his.12781

12. Rogers AC, Winter DC, Heeney A, Gibbons D, Lugli A, Puppa G, Sheahan K (2016) Systematic review and meta-analysis of the impact of tumour budding in colorectal cancer. Br J Cancer 115:831840. doi:10.1038/bjc. 2016.274

13. Karamitopoulou E (2012) Tumor budding cells, cancer stem cells and epithelial-mesenchymal transition-type cells in pancreatic cancer. Front Oncol 2:209. doi:10.3389/fonc.2012.00209

14. Kadota K, Nitadori J, Woo KM, Sima CS, Finley DJ, Rusch VW, Adusumilli PS, Travis WD (2014) Comprehensive pathological analyses in lung squamous cell carcinoma: single cell invasion, nuclear diameter, and tumor budding are independent prognostic factors for worse outcomes. J Thorac Oncol 9:1126-1139. doi:10. 1097/JTO.0000000000000253

15. Gujam FJ, McMillan DC, Mohammed ZM, Edwards J, Going JJ (2015) The relationship between tumour budding, the tumour microenvironment and survival in patients with invasive ductal breast cancer. Br J Cancer 113:1066-1074. doi:10.1038/bjc.2015.287

16. Xie N, Wang C, Liu X, Li R, Hou J, Chen X, Huang H (2015) Tumor budding correlates with occult cervical lymph node metastasis and poor prognosis in clinical early-stage tongue squamous cell carcinoma. J Oral Pathol Med 44:266-272. doi:10.1111/jop. 12242

17. Almangush A, Bello IO, Keski-Santti H, Makinen LK, Kauppila JH, Pukkila M, Hagstrom J, Laranne J, Tommola S, Nieminen O, Soini Y, Kosma VM, Koivunen P, Grenman R, Leivo I, Salo T (2014) Depth of invasion, tumor budding, and worst pattern of invasion: prognostic indicators in early-stage oral tongue cancer. Head Neck 36:811-818. doi:10.1002/hed.23380

18. Seki M, Sano T, Yokoo S, Oyama T (2016) Histologic assessment of tumor budding in preoperative biopsies to predict nodal metastasis in squamous cell carcinoma of the tongue and floor of the mouth. Head Neck 38(Suppl 1):E1582-E1590. doi:10.1002/hed. 24282

19. Piazza C, Montalto N, Paderno A, Taglietti V, Nicolai P (2014) Is it time to incorporate 'depth of infiltration' in the T staging of oral tongue and floor of mouth cancer? Curr Opin Otolaryngol Head Neck Surg 22:81-89. doi:10.1097/MOO.0000000000000038

20. Krakhmal NV, Zavyalova MV, Denisov EV, Vtorushin SV, Perelmuter VM (2015) Cancer invasion: patterns and mechanisms. Acta Nat 7:17-28

21. Brandwein-Gensler M, Smith RV, Wang B, Penner C, Theilken A, Broughel D, Schiff B, Owen RP, Smith J, Sarta C, Hebert T, Nason R, Ramer M, DeLacure M, Hirsch D, Myssiorek D, Heller K, Prystowsky M, Schlecht NF, Negassa A (2010) Validation of the histologic risk model in a new cohort of patients with head and neck squamous cell carcinoma. Am J Surg Pathol 34:676-688. doi:10. 1097/PAS.0b013e3181d95c37

22. Ueno H, Mochizuki H, Shinto E, Hashiguchi Y, Hase K, Talbot IC (2002) Histologic indices in biopsy specimens for estimating the probability of extended local spread in patients with rectal carcinoma. Cancer 94:2882-2891. doi:10.1002/cncr.10551

23. Wang C, Huang H, Huang Z, Wang A, Chen X, Huang L, Zhou X, Liu X (2011) Tumor budding correlates with poor prognosis and 
epithelial-mesenchymal transition in tongue squamous cell carcinoma. J Oral Pathol Med 40:545-551. doi:10.1111/j.1600-0714.2011. 01041.x

24. Attramadal CG, Kumar S, Boysen ME, Dhakal HP, Nesland JM, Bryne M (2015) Tumor budding, EMT and cancer stem cells in T12/N0 oral squamous cell carcinomas. Anticancer Res 35:61116120

25. Hori Y, Kubota A, Yokose T, Furukawa M, Matsushita T, Takita M, Mitsunaga S, Mizoguchi N, Nonaka T, Nakayama Y, Oridate N (2017) Predictive significance of tumor depth and budding for late lymph node metastases in patients with clinical N0 early oral tongue carcinoma. Head Neck Pathol. doi:10.1007/s12105-017-0814-1

26. Nakagawa Y, Ohira M, Kubo N, Yamashita Y, Sakurai K, Toyokawa T, Tanaka H, Muguruma K, Shibutani M, Yamazoe S, Kimura K, Nagahara H, Amano R, Ohtani H, Yashiro M, Maeda K, Hirakawa K (2013) Tumor budding and E-cadherin expression are useful predictors of nodal involvement in $\mathrm{T} 1$ esophageal squamous cell carcinoma. Anticancer Res 33:5023-5029

27. Luo WR, Gao F, Li SY, Yao KT (2012) Tumour budding and the expression of cancer stem cell marker aldehyde dehydrogenase 1 in nasopharyngeal carcinoma. Histopathology 61:1072-1081. doi:10. $1111 / j .1365-2559.2012 .04350 . x$

28. Tan WJ, Chia CS, Tan HK, Soo KC, Iyer NG (2012) Prognostic significance of invasion depth in oral tongue squamous cell carcinoma. ORL J Otorhinolaryngol Relat Spec 74:264-270. doi:10. $1159 / 000343796$

29. Jung J, Cho NH, Kim J, Choi EC, Lee SY, Byeon HK, Park YM, Yang WS, Kim SH (2009) Significant invasion depth of early oral tongue cancer originated from the lateral border to predict regional metastases and prognosis. Int J Oral Maxillofac Surg 38:653-660. doi:10.1016/j.ijom.2009.01.004

30. Ganly I, Goldstein D, Carlson DL, Patel SG, O'Sullivan B, Lee N, Gullane P, Shah JP (2013) Long-term regional control and survival in patients with "low-risk," early stage oral tongue cancer managed by partial glossectomy and neck dissection without postoperative radiation: the importance of tumor thickness. Cancer 119:11681176. doi:10.1002/cncr.27872

31. Han MW, Lee JC, Kim YM, Cha HJ, Roh JL, Choi SH, Nam SY, Cho KJ, Kim SW, Kim SY (2015) Epithelial-mesenchymal transition: clinical implications for nodal metastasis and prognosis of tongue cancer. Otolaryngol Head Neck Surg 152:80-86. doi:10. $1177 / 0194599814556061$
32. Huang SH, Hwang D, Lockwood G, Goldstein DP, O'Sullivan B (2009) Predictive value of tumor thickness for cervical lymph-node involvement in squamous cell carcinoma of the oral cavity: a metaanalysis of reported studies. Cancer 115:1489-1497. doi:10.1002/ cncr.24161

33. Goel V, Parihar PS, Parihar A, Goel AK, Waghwani K, Gupta R, Bhutekar U (2016) Accuracy of MRI in prediction of tumour thickness and nodal stage in oral tongue and gingivobuccal cancer with clinical correlation and staging. J Clin Diagn Res 10:TC01-TC05. doi:10.7860/JCDR/2016/17411.7905

34. Lodder WL, Teertstra HJ, Tan IB, Pameijer FA, Smeele LE, van Velthuysen ML, van den Brekel MW (2011) Tumour thickness in oral cancer using an intra-oral ultrasound probe. Eur Radiol 21:98106. doi:10.1007/s00330-010-1891-7

35. Mark Taylor S, Drover C, Maceachern R, Bullock M, Hart R, Psooy B, Trites J (2010) Is preoperative ultrasonography accurate in measuring tumor thickness and predicting the incidence of cervical metastasis in oral cancer? Oral Oncol 46:38-41. doi:10.1016/ j.oraloncology.2009.10.005

36. Preda L, Chiesa F, Calabrese L, Latronico A, Bruschini R, Leon ME, Renne G, Bellomi M (2006) Relationship between histologic thickness of tongue carcinoma and thickness estimated from preoperative MRI. Eur Radiol 16:2242-2248. doi:10.1007/s00330-0060263-9

37. S Kumar S GN, Anila K R, Sebastian P. (2015) Can frozen section be used to assess depth of invasion of early carcinoma of tongue? Oral Oncol 51:e87-e88

38. Lydiatt WM, Patel SG, O'Sullivan B, Brandwein MS, Ridge JA, Migliacci JC, Loomis AM, Shah JP (2017) Head and neck cancers - major changes in the American Joint Committee on cancer eighth edition cancer staging manual. CA Cancer J Clin 67:122137. doi:10.3322/caac. 21389

39. Sgaramella N, Coates PJ, Strindlund K, Loljung L, Colella G, Laurell G, Rossiello R, Muzio LL, Loizou C, Tartaro G, Olofsson K, Danielsson K, Fahraeus R, Nylander K (2015) Expression of p16 in squamous cell carcinoma of the mobile tongue is independent of HPV infection despite presence of the HPV-receptor syndecan-1. Br J Cancer 113:321-326. doi:10.1038/bjc.2015.207

40. Kang H, Kiess A, Chung CH (2015) Emerging biomarkers in head and neck cancer in the era of genomics. Nat Rev Clin Oncol 12:1126. doi:10.1038/nrclinonc.2014.192 